\title{
Educação e Direitos Humanos: educando para a conscientização, para a inclusão e para a humanização
}

Joño Ferreira SANTIAGo ${ }^{1}$

Resumo: Este artigo tem como objetivo relacionar educação e direitos humanos e mostrar as implicações dessa relação. Educar para os direitos humanos é educar para a liberdade, o que significa incluir e conscientizar. Destaca a importância e o papel que exerce o paradigma na nossa forma de pensar. Mostra a proximidade entre educar e cuidar, a educação e o cuidado, bem como o paradoxo existente em nosso tempo diante de tantas possibilidades de inclusão e de libertação e a realidade de exclusão, de segregação e de opressão. Relaciona a "educação" autoritária, alienadora e excludente com o patriarcalismo, sobretudo com relação às mulheres, e forte machismo como resquícios desse paradigma centralizador e que exclui as mulheres da plena dignidade humana, naturalizando a sua inferioridade. Mostra que educar para os direitos humanos exige um regime democrático e uma democracia deliberativa. Reconhece a educação como um ato político e, por isso mesmo, reconhece a politicidade do ato de educar. Tem como metodologia um referencial bibliográfico com duas bases de sustentação: o paradigma de Igreja em saída como mãe e educadora na fé do Papa Francisco; e a perspectiva de educação de Paulo Freire em três de suas principais obras (a pedagogia do oprimido, da autonomia e da esperança). Soma-se também a experiência do autor com a educação popular e leitura popular da bíblia nas Pastorais Sociais, nas Comunidades Eclesiais de Base (CEBs) e no Centro de Estudos Bíblicos (CEBI).

Palavras-chave: Educação. Paradigma. Inclusão. Diferença. Direitos Humanos.

\section{Education and human rights: educating for awareness, for inclusion and for humanization}

Abstract: This article aims to relate Education and Human Rights and demonstrate the implications of this relationship. Educating for human rights is educating for freedom, which means to include and raise awareness. It also highlights the importance and the role of the paradigm in our way of thinking. It shows the closeness between educating and caring, education and care and the existing paradox in our time in the face of so many possibilities of inclusion and liberation and the reality of exclusion, segregation and oppression. It also relates authoritative, alienating and excluding "education" with patriarchalism. Especially, regarding to women, and the strong 
machismo as remnants of this centralizing paradigm that excludes women from full human dignity, naturalizing their inferiority. This article shows that educating for human rights requires a democratic regime and a deliberative democracy. It recognizes education as a political act and as a result, it recognizes the politics of the act of educating. Its methodology is a bibliographic reference with two bases support. Namely: the paradigm of the outgoing church as a mother educator in the Pope Francis' faith, and the perspective of education of Paulo Freire in three of his major works. The pedagogy of the oppressed, The pedagogy of autonomy and The pedagogy of hope. Furthermore, the author's experience is added with popular education and popular reading of the Bible in social pastorals, ecclesial base communities (CEBs) and the Center for Biblical Studies (CEBI).

Keywords: Education. Paradigm. Inclusion. Difference. Human Rights.

\section{Educación y derechos humanos: educando para la concientización, para la inclu- sión y para la humanización}

Resumen: Este artículo tiene como objetivo relacionar educación y derechos humanos y mostrar las implicaciones de esta relación. Educar para los derechos humanos es educar para la libertad lo que significa incluir y concientizar. Destaca la importancia y el papel que ejerce el paradigma en nuestra forma de pensar. Muestra la proximidad entre educar y cuidar, la educación y el cuidado de la paradoja existente en nuestro tiempo ante tantas posibilidades de inclusión y de liberación y la realidad de exclusión, de segregación y de opresión. Relaciona la "educación" autoritaria, alienada y excluyente, con el patriarcado. Sobre todo, con relación a las mujeres, y fuerte machismo como resquicios de este paradigma centralizador que excluye a las mujeres de la dignidad humana, naturalizando su inferioridad. Muestra que, educar para los derechos humanos exige un régimen democrático y una democracia deliberativa. Reconoce la educación como un acto político y por eso mismo, reconoce la política del acto de educar. Tiene como metodología un referencial bibliográfico con dos bases de sustentación. A saber: el paradigma de la Iglesia en salida como madre y educadora en la fe del Papa Francisco, y la perspectiva de educación de Paulo Freire en tres de sus principales obras. La pedagogía del oprimido, de la autonomía y de la esperanza. Se suma también la experiencia del autor con la educación popular y lectura popular de la Biblia en las Pastorales Sociales, en las Comunidades Eclesiales de Base (CEBs) y en el Centro de Estudios Bíblicos (CEBI).

Palabras clave: Educación. Paradigma. Inclusión. Diferencia. Derechos Humanos.

\section{Introdução}

Buscamos mostrar neste artigo alguns aspectos da relação existente entre educação e humanização, por isso ele trata da importância de educar para os direitos humanos e procura mostrar a relação entre educação, libertação, conscientização e inclusão. Educar é libertar e incluir. É marcado e talvez limitado pelos olhares bíblico, teológico e cristão de seu autor. Nasce de suas vivências 
como teólogo leigo nas Comunidades Eclesiais de Base (CEBs) e no Centro de Estudos Bíblicos (CEBI); da esperança teimosa que faz das Pastorais Sociais essa Igreja que colhe espigas no dia de sábado (Mt 12,1-8); da Igreja-Mãe em saída, de coração, portas e braços abertos, anunciada pelo Papa Francisco (2014, no 46); e da pedagogia do oprimido do educador e humanista Paulo Freire. Quer e busca chamar a atenção para os paradigmas que antecedem o nosso pensar. Aponta para a necessidade de superarmos paradigmas fossilizados na educação, na política, na teologia e na religião. E propõe uma atualização e uma reinterpretação desses paradigmas para que possamos ressignificar as nossas ações educativas. Este texto propõe educar para as diferenças, para a convivência com o diferente. E isso exige mudança de paradigma; exige uma esperança militante que nos lembre a cada instante que "Mudar é difícil, mas possível" (FREIRE, 2004, p. 81). E essa mudança é o que deve fazer a educação que não transforma, não traz mudanças, não serve e não é educação. Quando pensamos a partir de um novo paradigma, descobrimos, por exemplo, que é mais fácil multiplicar do que partilhar o pão (Jo 6,1-15). Para o cientista Albert Einstein (apud BOFF, 2012, p. 148), "é mais fácil desintegrar um átomo do que remover um preconceito da cabeça de uma pessoa". Educar para os direitos humanos, portanto, é educar para a superação dos preconceitos e para o reconhecimento das diferenças como qualidades que revelam as nossas incompletudes.

\section{O paradoxo de nosso tempo e a educação para o cuidado necessário}

Quando paramos e refletimos sobre a sociedade atual, deparamo-nos com um paradoxo. Possivelmente, jamais tivemos tantas condições materiais e objetivas para assegurar os direitos humanos fundamentais a todos os habitantes, incluindo-os e garantindo-lhes o direito à alimentação adequada, em quantidade e qualidade suficientes, à moradia digna, com saneamento básico, ao trabalho como um dom e realização das obras; por isso, é lugar de encontro com a felicidade. A Literatura Sapiencial, no Livro do Eclesiastes (Coélet), fala-nos de "desfrutar do trabalho" (Ecl 3, 22; 5, 17-19), da educação de qualidade e em condições que nos permitam desenvolver-se humana, psicológica, intelectual, cultural e espiritualmente. Partindo do direito humano a ter direitos, chegaremos à dignidade plena da vida, aquilo que a comunidade do discípulo amado que escreveu o Evangelho de São João chamou de vida em abundância (Jo 10,10).

Aqui se inclui o direito de ser e de se reconhecer, mas igualmente ser reconhecido como um ser livre. Possivelmente, entretanto, conhecendo as possibilidades existentes, talvez estejamos diante da maior negação de direitos da história humana. É certo que, do ponto de vista da comunicação, seja pelos avanços tecnológicos, seja pelas formas desenvolvidas de comunicar-se, trazidas pela tecnologia, esse é um tempo ímpar em possibilidades. Comunicar-se é um direito, 
uma condição e, ao mesmo tempo, uma necessidade humana. É por meio da comunicação que acontece o processo educativo humano, que inclui, conscientiza, humaniza e liberta. É por intermédio da comunicação que se chega à consciência de ser humano como um ser de direitos: o direito ao livre pensamento, a pronunciar a sua palavra, à ir e vir sem constrangimentos ou restrições. $\mathrm{O}$ direito a manifestar-se com liberdade, política, cultural e religiosamente.

A educação diante dessas afirmações feitas deve, por fim, educar para o cuidado. Em sua reflexão sobre o cuidado necessário, o teólogo franciscano Leonardo Boff (2012, p. 57) faz essa importante afirmação: "Sem ser cuidado permanentemente, antes, durante e depois de tudo o que é e empreende, o ser humano deixaria de existir". Ser permanentemente incluído nos cuidados de alguém é um direito fundamental e uma necessidade humana. Ter permanentemente alguém incluído em seu cuidado é o grande imperativo ético humano. É para isso que a educação deve nos preparar. Alguém, aqui, deve ser entendido no sentido includente, ou seja, mais que pessoas. Já é passada a hora de a educação, ou os processos educativos como um todo, ensinar-nos que a Terra é um ser vivo. É mãe e cuida de nós, mas, como todas as mães humanas, também precisa dos nossos cuidados.

A educação, para além do ato de ir à escola, de estudar, de receber títulos e diplomas e, até mesmo, de ter "bons comportamentos", pressupõe mudança de paradigmas. Educar, então, é incluir, e educar-se é abrir-se à inclusão, incluindo e deixando-se incluir. É essa abertura que nos liberta, e é também essa liberdade que nos abre para a conscientização. E em que consiste essa conscientização? Em saber e reconhecer que o outro existe e que não tem apenas o direito de existir, mas, para que eu seja, ele precisa ser. A abertura ao outro, às suas ideias, à sua cultura, à sua forma de ser religioso e de viver a sua espiritualidade. O outro, nesse sentido, é um ser completo, total, que não pode ser apenas o meu diferente, o meu contraditório ou o "não eu". Na estrada do pensamento de Martin Buber, Paulo Freire (2006, p. 192) pedagogiza uma relação dialógica do eu-tu: "Não há, portanto, na teoria dialógica da ação, um sujeito que domina pela conquista e um objeto dominado. Em lugar disto, há sujeitos que se encontram para a pronúncia do mundo, para a sua transformação". Ele existe e merece ser reconhecido. É para essa relação entre sujeitos, em que ambos estão igualmente sendo, e não para uma relação sujeito-objeto, em que ser sujeito é ter, que a educação para a liberdade acontece.

\section{A mudança de paradigma e a exclusão}

Quando falamos de mudança de paradigma, entendemos o paradigma como aquilo que antecede o pensar. Para que fique ainda mais compreensível, é como o nascedouro dos nossos pensamentos. Pensamos segundo o paradigma 
que nos orienta. Se mantemos o paradigma de educação como algo que acontece somente na escola, reforçamos a ideia preconceituosa e excludente de que uns sabem e outros não sabem; se não mudamos o paradigma da escola como o único lugar de educação, legitimamos a escola como lugar de exclusão; se igualmente alimentamos o paradigma de que inclusão é apenas inserir alguém em um espaço exclusivo, continuamos segregando, e não incluindo de fato; se aceitamos o paradigma de liberdade que diz ser ela dada generosamente a alguém inferior por outro alguém superior, estaremos falando de dominação, e não de libertação; se ainda, de forma semelhante, damos vida ao paradigma de direito como sendo algo preso à condicionantes, estamos falando de outra categoria que não direitos humano. Aqui entra com toda força o paradigma de políticas públicas, as quais não podem nem devem ser condicionadas, pois, antes, são direitos.

Se agimos a partir do pensamento que ter direito ao acesso às políticas sociais é necessário cumprir alguma regra, responder desta ou daquela forma, dificilmente estaremos falando de inclusão e de direitos humanos. A começar pelo direito à vida, seria temerário aceitar qualquer condicionamento para que alguém ou alguma forma de vida exista. A educação não pode excluir impedindo de existir, sob quaisquer argumentos, a defesa incondicional da vida. Sobre a abrangência e o alcance da exclusão, é oportuno termos presente o que diz o professor português David Rodrigues (2006, p. 9):

A exclusão tornou-se uma espécie de epidemia do início deste século: assustadora como a peste, altamente contagiosa e de cura pouco provável. Esta "epidemia social" demonstra uma grande vitalidade e dinâmica e, devido ao seu rápido alastramento, tem sido tratado como uma das ameaças mais sérias ao desenvolvimento das sociedades, em cujos objetivos cada vez mais se inclui a sua erradicação.

O início do século XXI, conforme diz o professor David, trouxe-nos, com todas as descobertas científicas e invenções tecnológicas que representou, as possibilidades de um verdadeiro desenvolvimento humano, econômico e social. Aqui, talvez possamos verificar uma situação latente de conceito equivocado de paradigma. O que víamos, e que ainda continuamos vendo, é o crescimento econômico, e não necessariamente o desenvolvimento. As economias nacionais cresceram nesses anos com a exclusão das multidões de seres humanos, homens e mulheres, condenados às mais diversas formas de exclusão, desde a juventude, a adolescência, a infância e, por que não dizer, até mesmo, desde antes de nascerem. E quais são, então, as causas de tão cruel exclusão? A classe social, a etnia, o gênero, o lugar geográfico onde nascem, onde se criam e de onde vêm. Não obstante todas essas causas estejam relacionadas e correlacionadas, naturalizou-se o falso e cruel paradigma da meritocracia, que somente um elitismo absolutamente desacompanhado de humanidade pode defender. 
O que vemos, grosso modo, sobretudo na educação, é o paradigma da inteligência como atributo exclusivo das classes dominantes, o que significa dizer gente branca, das classes média e alta. São eles quem mais nos revelam as mazelas de uma cultura da exclusão. Não são, sequer, incluídos; antes, são segregados nos próprios egoísmos, pois a "educação" que os faz parecer mais inteligentes, mas merecedores de tudo, os desumaniza a ponto de não se contentarem com ter muito, pois querem ter tudo, principalmente à custa do nada ter de milhões de outros seres humanos e da ameaça à diversidade de vida do planeta. São segregadores, que até admitem que se façam assistencialismos para os pobres, desde que os mantenham distantes de si e de seus filhos. É dever da educação conscientizar para essa realidade.

Como não trazer presente um cartaz carregado por membros de uma passeata, se não da elite, mas em nome dela, em 2016? Em tal cartaz lia-se em português bem escrito: "É inadmissível aceitar que meu filho vá para a mesma sala de aula do filho de minha empregada". Logo atrás podia-se ler em outro cartaz: “Eu quero o meu país de volta!". Parafraseando um clássico da música popular brasileira, a pergunta que não quer calar é: que país é esse? Menos de três anos depois, tudo parece mais compreensível. O país que eles queriam de volta era o país da exclusão naturalizada como política de Estado. Porém, como nos é negado o direito humano à comunicação democrática, essa discussão ainda não começou para valer.

Falemos um pouco sobre a liberdade. Educar para a liberdade é educar para a inclusão. E não são dois limites agudos da educação? Libertar e incluir? Nesse sentido, libertar é acolher, e acolher é libertar. Quando o Apóstolo Paulo, com os seus irmãos de caminhada, escreveu a Carta aos Gálatas, em torno do ano 55 d.C., em Éfeso, deixou-nos uma importante diretriz, mostrando-nos os laços entre liberdade e inclusão (ver Gl 5,1-6): "É para a liberdade que Cristo nos libertou" (v 1), diz o Apóstolo dos gentios. E logo em seguida trata de mostrar o fio que liga a liberdade à inclusão.

Se digo para alguém "vá, você está livre", mas não incluo esse alguém nas minhas relações, na minha confiança, na minha lista de cuidados e, até mesmo, nas minhas orações, esse alguém dificilmente ficará livre por muito tempo. Por isso, diz Paulo: "Fiquem firmes, portanto, e não se deixem prender de novo ao jugo da escravidão" (v 2). Nem sempre a pior prisão é aquela causada por paredes, grades ou correntes. A prisão da desconfiança, do preconceito e da discriminação é terrível! E o que dizermos da prisão da indiferença? E como nos libertar da prisão da alienação política que continua tratando tudo isso como um fatalismo e um determinismo inexorável? O teólogo belga Adolphe Guesché (2005, p. 41), ao falar sobre o sentido, apresenta-nos a liberdade como elemento central do sentido. "Assim chegaríamos a compreender melhor a liberdade. A liberdade é altamente racional: sem ela o ser humano não é ser humano (animal 
rationale), mas seu fundamento está ligado a origem mais alta, fundadora”. Dito de outro jeito, para reconhecermos alguém como um ser livre, antes precisamos incluí-lo como ser humano. E o ser humano é um animal racional, mas transcende essa dimensão. Uma educação que ignora ou nega isso não é humana, não inclui nem liberta.

A sabedoria popular não tem muita a atenção das ciências e parece não caber mesmo na caixinha apertada da linguagem acadêmica. Mas ouvimos com frequência e possivelmente até já pronunciamos uma expressão popular reveladora do quanto desejamos a inclusão. Trata-se da expressão: "Me inclua fora dessa". Até na hora de falar da exclusão (vivida, sentida e imposta), o povo prefere falar primeiro da inclusão (desejada, sonhada e negada). Não seria essa uma forma de denúncia velada de uma exclusão revelada? Não seria essa frase o anúncio de uma esperança militante e subversiva, mesmo que ferida? De qualquer forma, trata-se da fala de alguém livre, ao menos das regras e normas da língua culta. Essa é também uma das formas de exclusão. Excluir as palavras e as formas de dizê-las que o povo tem são, antes, formas de resistência.

A escola e a "educação" excludentes e "Seus preconceitos. Suas deformações, entre estas, a desconfiança do povo. Desconfiança de que o povo seja incapaz de pensar certo. De querer. De saber" (FREIRE, 2006, p. 53). A opção mais frequente dos textos acadêmicos é fazer ciência. Porém, na linha do professor Moacir Gadotti (2004, p. 57), “[...] Por isso é mais fácil escrever sobre os outros, a natureza, o universo. É mais fácil fazer ciência do que falar de si mesmo”. O trocadilho, o jogo de palavras, o aparente desdém da própria situação são alegorias que deixam o ato de comunicar-se mais belo porque é mais real. É poesia isso. Não é, certamente, apenas uma questão de linguagem, mas é também por uma questão de linguagem que a escola prefere punir e excluir a ouvir, a dialogar e a aprender com os que deseja ensinar. E continua: "Não basta gostar de aprender. É preciso saber como aprender, como estudar. Isso os professores não ensinam" (FREIRE, 2006, p 107). E, se falamos de uma escola que não ensina como aprender, como estudar? "Me inclua fora dessa".

\section{A educação católica e a formação de seres para a inclusão}

A Igreja é uma instituição educativa e tem grande destaque no mundo da educação. Isso nos parece inegável. Embora saibamos que essa afirmação valha para todas as igrejas, aqui, quando falamos Igreja, referimo-nos à Igreja Católica Apostólica Romana. As perguntas que nos movem é: a educação católica não reproduz os vícios de uma "educação" por vezes tão tecnicista, cuja finalidade é formar mão de obra para o mercado de trabalho? Em que difere da educação das grandes instituições capitalistas e que sobrevivem capitalistamente, vendendo fragmentos de saber, pingos de conhecimento a conta-gotas? Formar um ser 
humano para ser cada vez mais humano deve preceder à formação profissional. É, inclusive, a nosso ver, condição para que se formem bons profissionais. Existem diferenciais significativos com relação à exclusão étnica, social, ecológica, política de gênero e à conscientização para a solidariedade universal nas escolas católicas? O Papa Francisco (2015) vem colocando essas questões no centro das preocupações pedagógicas da Igreja:

A consciência da gravidade da crise cultural e ecológica precisa traduzir-se em novos hábitos. Muitos estão cientes de que não basta o progresso atual e a mera acumulação de objetos ou prazeres para dar sentido e alegria ao coração humano, mas não se sentem capazes de renunciar àquilo que o mercado lhes oferece $\left(\mathrm{n}^{\circ} 209\right)$.

Dizemos ser essa uma preocupação que habita os horizontes da educação católica, vista como instrumento de inclusão, humanização e libertação. Não obstante, Francisco (2015) conclui dizendo: "Por isso, estamos perante um desafio educativo" (n 209). A educação tem o dever de nos levar à mudança de hábitos. Educação que não transforma não serve. Será a partir de novas atitudes que confirmaremos a conversão pastoral urgente e necessária. Atitudes que comprovem uma nova consciência ecológica e que nos façam nadar contra a maré da correnteza do consumismo sem critérios, e que isso ocorra sob a orientação de novos itinerários pedagógicos do cuidado e da autorresponsabilidade. É preciso incluir o diálogo nos espaços educativos e com ele um novo reordenamento dos valores.

E urgente, portanto, uma prática educativa que reconheça e propague uma consciência do que é essencial e do que é secundário; que tenha coragem de dizer que, por mais importantes que sejam as coisas, as pessoas sempre as antecedem. Pois, para Francisco (2015): "É muito nobre assumir o dever de cuidar da criação com pequenas ações diárias, e é maravilhoso que a educação seja capaz de motivar para elas até dar forma a um estilo de vida" ( $\left.\mathrm{n}^{\circ} 211\right)$. Educar para a inclusão e para a liberdade é a chave que abre a nossa consciência para o cuidado. Assim nos diz o Papa Francisco (2015): "Na verdade, a pessoa humana cresce, amadurece santifica-se tanto mais, quanto mais se relaciona, sai de si mesma para viver em comunhão com Deus, com os outros e com todas as criaturas ( $\left.\mathrm{n}^{\circ} 240\right)$. Relacionar-se é incluir e também incluir-se.

Somente uma educação que educa com alegria e nos desperta para o encontro com outro como sujeito de sua própria existência e como ser de direitos pode nos fazer seres da alegria. A alegria do Evangelho é que nos faz seres de luz. É preciso sair dos labirintos conceituais que nos colocam ao centro e nos impõem medos e nos fazem ver o outro como ameaça por causa da sua religião, etnia, orientação sexual, situação conjugal, situação econômica, do seu jeito de ser, enfim. Reconhecermos um ser inacabado e que é o inacabamento do outro nos faz seres mais humanos e conscientes de suas limitações. Fecharmos em 
dogmas, doutrinas, ideologias ou "verdades" que nos colocam em pedestais, enquanto oprimem os outros, é receita de exclusão. Ao contrário dos vinhos, as metodologias não são melhores à medida que envelhecem. Elas costumam perder a validade e precisam frequentemente ser atualizadas e até substituídas. Sair significa abrir-se, incluir, incluir-se. Senão, vejamos:

Saiamos, saiamos para oferecer a todos a vida de Jesus Cristo! Repito aqui, para toda a Igreja, aquilo que muitas vezes disse aos sacerdotes e aos leigos de Buenos Aires: prefiro uma Igreja acidentada, ferida e enlameada por ter saído pelas estradas a uma Igreja enferma pelo fechamento e pela comodidade de se agarrar às próprias seguranças. Não quero uma Igreja preocupada com ser o centro, e acaba presa num emaranhado de obsessões e procedimentos. Se alguma coisa nos deve santamente inquietar e preocupar a nossa consciência é que haja tantos irmãos nossos que vivem sem a força, a luz e a consolação da amizade com Jesus Cristo, sem uma comunidade de fé que os acolha, sem um horizonte de sentido e de vida. Mais do que o temor de falhar, espero que nos mova o medo de nos encerrarmos nas estruturas que nos dão uma falsa proteção, nas normas que nos transformam em juízes implacáveis, nos hábitos em que nos sentimos tranquilos, enquanto lá fora há uma multidão faminta e Jesus repete-nos sem cessar: "Dai-lhes vós mesmos de comer” (Mc 6,37) (PAPA FRANCISCO, 2015, nº 49).

Estamos diante de uma situação concreta de inclusão. Sair, nesse caso, é mais do que um movimento físico de mudar de lugar. Sair dos paradigmas que geram pensamentos mofados e envenenados pelos fundamentalismos e determinismos que alimentam preconceitos; que excluem e segregam. Sair das dependências que nos fazem escravos de estruturas frias e sem vida. Sair de uma educação clericalizada e de uma educação dogmática, que fossilizam ideias e pensamentos e que segregam pessoas. Sair, no entanto, exige sentir o desconforto existente e comum às zonas de conforto.

\section{Educar para os direitos humanos e superar o patriarcalismo}

Faz-se necessário não apenas dizer, mas repetir e, mais do que simples repetição papagaista, buscar exemplos de convivência com o diferente. É urgente que a educação inclua em suas metodologias, mas, sobretudo, em suas práticas educativas, as diferenças como valores de crescimento. A diferença é uma riqueza, e não uma pobreza. Tratar a diferença como se fosse uma desigualdade é um equívoco que costuma nos levar a cometer crimes. A começar pela questão de gênero tão mutilada em seu sentido tanto na educação como nas discussões, feita como queda de braço. Pelo que se pode concluir, tendo por referência a forma como se expressa na discussão sobre gênero na sociedade atual, temos os 
resquícios de um machismo ridículo, o qual, por sua vez, é a expressão tardia e resistente de uma sociedade patriarcalista que já não cabe mais na atual realidade. Por isso, manifesta-se de forma tão violenta!

É insustentável sob quaisquer argumentos ou perspectivas a inferioridade da mulher perante o homem. Porém, não são raras as formas de naturalização dessa deformação das relações. Basta que olhemos, a partir de um paradigma atualizado, as representações femininas na política. Para não nos perdermos em números vergonhosos dessa representação, basta-nos aqui lembrar que temos cotas de participação de mulheres nas eleições. Trinta por cento das candidaturas para cargos legislativos, obrigatoriamente, devem ser de mulheres. Por si só essa é uma denúncia grave, sabendo que elas são mais da metade da população. A primeira dimensão de importância das cotas é esta: denunciar um desequilíbrio, uma injustiça, uma exclusão vexatória, para dizer o mínimo, da mulher nas decisões. E, consequentemente, anunciar o início de um processo de superação.

Possivelmente, a Campanha da Fraternidade seja um dos momentos mais educativos com relação aos direitos humanos. E não apenas na Igreja, mas em toda a sociedade. Ao tratar, no ano de 2018, do tema da violência e na perspectiva de sua superação, a Conferência Nacional dos Bispos do Brasil (CNBB) nos traz grande contribuição. Antes, porém, vejamos a violência como o fruto de uma exclusão generalizada. É multidimensionada, pois, além da questão de gênero, vemos as questões étnicas e religiosas, os migrantes, os refugiados, os homossexuais, os jovens e as questões econômicas. A exclusão aqui é vista para além de segmentos sociais, como uma cultura da exclusão, a partir da insuficiência do Estado ou da total ausência de políticas públicas. Denuncia-se a insuficiência e até mesmo a incapacidade do Estado de garantir os direitos fundamentais para a maioria da população. Educar para os direitos humanos exige que os ambientes educativos, de forma especial a escola, debata e aponte formas de superação de uma realidade de guerra.

As vítimas de homicídios são, em maior parte, homens. Porém, entre 2001 e 2011, o aumento de assassinatos de homens foi 8,1\%, enquanto que os assassinatos de mulheres cresceram 17,2\%. Portanto, o homicídio de mulheres passou, nesse período, por uma tendência de alta. Somente no ano de 2013, houve 4,8 homicídios por cem mil mulheres - 13 homicídios diários, em média -, o Brasil ocupa a quinta colocação em uma lista de 83 países. Ocorreram aqui 2,4 vezes mais homicídios de mulheres do que a média internacional (CNBB, 2017, p 31).

A violência contra a mulher, como modo de dominação, de exclusão e de patrimonialismo, em que a mulher é vista como patrimônio do homem, manifesta-se, sobretudo, na forma. O que significam as palavras "educação" e "direitos humanos" no contexto em que apresentamos aqui? Segundo a CNBB (2017, p. 32): 
Uma pesquisa realizada pelo Fórum Brasileiro de Segurança Pública mostrou que, em 2015, o país registrou 45.460 casos de estupro. Porém, o levantamento estima que devem ter ocorrido entre 129,9 mil e 454,6 mil estupros no Brasil em 2015.

Precisamos urgentemente de uma educação que inclua temas como esses não apenas nos seus conteúdos, mas no debate e nos seus objetivos como busca de superação.

Os dados apresentados nos mostram uma situação de absoluta exclusão da mulher em sua dignidade humana. E, para que possam praticar tão hediondo crime, os "homens" que o cometem são desumanizados, estado em que, por consequência, a escola e a sociedade encontram-se igualmente desumanizadas, haja vista que: "A violência contra a mulher ocorre, principalmente, dentro de casa: 71,8\% das agressões registradas pelo SUS em 2011 aconteceram no domicílio da vítima" (CNBB, 2017, p. 32). A educação, não apenas na escola, mas nas famílias, nas igrejas e na sociedade, está educando para superar esse estado de desumanização, principalmente dos homens? Essa parece ser a pergunta geradora que brota em decorrência da realidade.

A palavra que gera esperança e dá sentido à uma educação para os direitos humanos é democracia! É a democracia a forma mais humana e conhecida, a nosso ver, de governar para/com todos. Somente uma forma de se viver que não apenas permita o diálogo, mas o promova, é capaz de incluir, conscientizar e educar para a liberdade. Precisamos acreditar na democracia como forma de humanização das pessoas, das relações e da sociedade; em que as diferenças existam, sejam conhecidas e reconhecidas, e não sejam transformadas em desigualdades. É a naturalização da desigualdade que naturaliza a exclusão, permitindo e até exigindo que uns, por essa ou por aquela razão, sejam excluídos. Dessa forma, homens e mulheres serão diferentes, mas iguais em dignidade. Para se chegar a esse estágio tão necessário e urgente, a nosso ver, teremos que superar os paradigmas administrativos que deformam a compreensão de ser humano, a saber: o patrimonialismo, que vê tudo como coisa e patrimônio, e o gerencialismo, para quem tudo é cliente e assim deve ser tratado. Na linha de uma proposta de democracia deliberativa, Carleial, Opuszka e Kanufre (2016, p. 188) afirmam:

Não por acaso, aliás, por isto mesmo, denuncia-se desde o início os modelos de gestão que mantém a cultura ditatorial, autoritária e assistencialista. A saber, o gerencialismo e o patrimonialismo, ambos se estruturam ao focar processos internos sem levar em conta a democratização do Estado, apresentando a relação clientelista e de certa forma impositiva e dominadora. Tem-se, por fim, como referencial desta proposta, o momento em que vive a cidade, com uma gestão democrática e transparente, pautada no humanismo que está na gênese do deliberativo. 
A inclusão como política de Estado, entendida como direito humano e dever do Estado, exige democratização da política e cidadãos conscientes de seu estar no mundo e comprometidos com a justiça, a partir de um Estado democrático, transparente e em todas as suas instâncias. Em última análise, mas também em seu início, quem exclui é o Estado. Mas o que é o Estado? Por mais que se façam desvios e se busquem fugas, o Estado somos todos. Quando ele exclui, nós, de alguma forma, mesmo que por omissão, estamos também excluindo, quando, no mínimo, permitimos que haja exclusão. É isso o que chamamos aqui de naturalização da exclusão. Certos segmentos, determinadas pessoas, alguns setores, "podem” ser excluídos. Há um paradigma da exclusão que orienta um pensar, inclusive, por mais cruel que isso possa parecer, do próprio excluído. É daí que dizemos que o assistencialismo é visto e aceito como política de governos em diferentes níveis e recorrente no tempo e nos mais diversos matizes ideológicos.

\section{A educação como um ato político}

Hoje vivemos momentos adversos para a educação. Os resquícios do patrimonialismo e do gerencialismo, presentes no patriarcalismo, conscientes em quem a promove e quase sempre inconsciente em quem a apoia, defendem a escola sem partido. Grosso modo, sem aprofundar a discussão nesse ponto, pois ele não é central nesta reflexão, essa é a forma mais explícita de se naturalizar a exclusão. E para a ideologia patriarcal, expressa em um subproduto de nome machismo, a escola é para formar mão de obra. O paradigma de trabalho que sustenta, sobretudo, a ideologia neoliberal não admite uma educação que ensina a pensar. Para seus gurus, "educação" é treinamento, no máximo doutrina. Deve ensinar a executar tarefas e a obedecer. Aqui reside a crueldade da desumanização, porque inteligência, política, educação de verdade, decisão, escolha, opinião, liberdade, inclusão e direitos são exclusivos atributos de homens, brancos, héteros e ricos.

A partir de paradigmas fossilizados, torna-se impossível compreender a politicidade inerente à educação que Paulo Freire apresentou na segunda metade do século XX, basicamente porque a depreciação conceitual está presente tanto na forma como compreendem a educação quanto na política. Esta, por sua vez, é concebida como uma espécie de doença contagiosa da educação, transmitida por professores que, por serem doentes, oferecem grande risco à sociedade e aos seus filhos. Na sua pedagogia da autonomia, Paulo Freire (2004, p. 110) diz:

É na diretividade da educação, esta vocação que ela tem, como ação especificamente humana, de "endereçar-se até sonhos, ideais, utopias e objetivos, que se acha o que venho chamando politicidade da educação. A qualidade de ser política, inerente à sua natureza. É impossível, na verdade, a neutralidade na educação. E é impossível, não porque professoras e professores "baderneiros" 
e "subversivos" o determinem. A educação não vira política por causa da decisão deste ou daquele educador. Ela é política. Quem pensa assim, quem afirma que é por obra deste ou daquele educador, mais ativista que outra coisa, que a educação vira política, não pode esconder a forma depreciativa como entende a política. Pois é na medida mesma em que a educação é deturpada e diminuída pela ação de "baderneiros" que ela, deixando de ser verdadeira educação, passa a ser política, algo sem valor.

Somente uma "educação" excludente pode formar seres passivos que aceitam resignadamente uma "política" opressora segregadora, que naturaliza a exclusão e divide os seres humanos em dois níveis: um que manda, que tudo pode e que tudo sabe, e outro que obedece, nada pode e nada sabe. O primeiro, obviamente, é composto pelas classes dominantes. Para a visão dominante, ser diferente soa como um defeito, uma doença talvez contagiosa. Diferentes são os outros, de outra classe social. Por isso, a necessidade de separação dos "diferentes" (pobres, negros, pessoas com deficiência, homossexuais etc.) dos "normais" (ricos, brancos, héteros, "perfeitos"). É dessa forma que a diferença se torna desigualdade. Vejamos, por exemplo, o que nos diz sobre ser diferente o professor David Rodrigues (2006, p. 306), ao tratar da educação inclusiva:

O certo é que não só os alunos são diferentes, mas também os professores - e ser diferente é uma característica humana e comum, não um atributo (negativo) de alguns. A EI dirige-se assim aos "diferentes", isto é, a todos os alunos. E é ministrada por "diferentes", isto é, por todos os professores.

Temos aqui, nas palavras do professor David, as marcas de um novo paradigma: de educação e de diferença. Ressaltamos o fato de despertar-nos a atenção para o conceito de política que cada paradigma traz.

\section{Educar para o direito humano a um planeta habitável e cheio de diversidades}

Ainda dá tempo. Começar este tópico com essa frase é esperançar a esperança no ser humano, no planeta, na vida e na casa comum. É acreditar e dizer para que outros também acreditem que nós somos seres educáveis e que a educação transforma as pessoas, muda as suas atitudes, ressignifica o seu pensar, atualiza seus comportamentos e as leva a mudança de paradigma. Todas as gerações têm seres especiais que, sobretudo como educadores, marcam seu tempo e promovem mudanças de atitudes. Eles são chamados de profetas (Isaías), santos (Francisco de Assis), ambientalistas (Chico Mendes), poetas (Suassuna) e até anjos. O nosso tempo também os tem. 
O Papa Francisco, por exemplo, projeta-se como o grande educador-profeta-pastor, cuja espiritualidade educa pelo exemplo e pela coragem. Francisco, o Papa do fim do mundo, renova as nossas esperanças e a de todas as espécies de vida que ainda resistem. Ele nos lembra algo importante, mesmo indo na contramão do que ouvimos sobre a juventude. Diz o Papa Francisco (2015, $\left.n^{\circ} 13\right)$ : "Os jovens exigem de nós uma mudança; interrogam-se como se pode pretender construir um futuro melhor, sem pensar na crise do meio ambiente e nos sofrimentos dos excluídos". Os jovens esperam de nós o testemunho do cuidado. Outro educador das primeiras décadas do cristianismo, Paulo de Tarso também nos deixou lições que a juventude e as futuras gerações esperam que as transmitamos: "Pois bem, sabemos que a criação inteira geme e sofre até agora com dores de parto" (Rm 8, 22).

Para além da consciência de que a terra é um ser vivo, pois até sente dores e geme, os animais também o sentem. Ou não? Quando nos "divertimos" com as "festas" de rodeio, com as pescas "esportivas", que educação estamos praticando? Será que os touros, os cavalos e as mulas não sentem dor? Será que os peixes "generosamente" soltos por nós depois da "diversão" não ficam machucados? Eles também não sentem dor? Na prática, ao agirmos assim, nós estamos ensinando para crianças, adolescentes e jovens que, com touros, cavalos, mulas e peixes, pode! No entanto, Papa Francisco (2015, no 130):

Recorda, com firmeza, que o poder humano tem limites e que "é contrário à dignidade humana fazer sofrer inutilmente os animais e dispor indiscriminadamente das suas vidas". Todo o uso e experimentação "exige um respeito religioso pela integridade da criação".

Incluir os animais no nosso cuidado também é conscientizar e educar para a liberdade.

Em que medida esses temas e essas questões fazem parte de forma importante dos processos educativos? Se não fazem, a pergunta é: por quê? Educar para os direitos humanos é educar para o cuidado, para a sensibilidade e para afetividade. Que devem ser para com as outras pessoas, mas também e igualmente para toda a criação. Afinal, a nossa maior característica, além das diferenças, é a interdependência. São pressupostos orientadores de qualquer processo educativo. Não há espécie que seja absolutamente independente e que não precise de outras espécies de vida para continuar vivendo. Chega a ser temerária uma educação que não educa a partir desses pressupostos. Educação é e precisa ser sempre praticada como um ato de amor.

É muito nobre assumir o dever de cuidar da criação com pequenas ações diárias, e é maravilhoso que a educação seja capaz de motivar para elas até dar forma a um estilo de vida. A educação na responsabilidade ambiental pode incentivar vários comportamentos que 
têm incidência direta e importante no cuidado do meio ambiente, tais como evitar o uso de plástico e papel, reduzir o consumo de água, diferenciar o lixo, cozinhar apenas aquilo que razoavelmente se pode comer, tratar com desvelo os outros seres vivos, servir-se dos transportes públicos ou partilhar o mesmo veículo com várias pessoas, plantar árvores, apagar as luzes desnecessárias... Tudo isto faz parte de uma criatividade generosa e edificante, que põe a descoberto o melhor do ser humano. Voltar - com base em motivações profundas - a utilizar algo em vez de desperdiçá-lo rapidamente pode ser um ato de amor que exprime a nossa dignidade (PAPA FRANCISCO, 2015, no 211).

A criatividade está mais na capacidade de cuidar da Terra como a nossa casa comum - e única - do que nas habilidades que nos fazem responder a questões feitas nas provas e nas notas que recebemos, apesar de que as escolas e as universidades continuam privilegiando as notas. Antes de propagarmos a cidadania do Reino, ou a dupla cidadania (Jo 13, 1-2; Ap 21, 1-4; Hb 11, 8-10; At $1,8)$, tantas vezes apresentada de forma mágica, precisamos garantir plenamente a cidadania política e social. Com ela chegaremos à cidadania planetária (BOFF, 2012). O planeta também tem os seus direitos e a sua cidadania. Aí sim, a partir das dimensões pessoal, comunitária, social e planetária, poderemos dignamente como cidadãos do Reino exercer a cidadania plena e tripla. É isso o que dizemos ser missão da educação que inclui, que liberta e que conscientiza.

\section{Considerações finais}

Educação e humanidade são, em certa medida, sinônimos. Educar é humanizar e humanizar exige uma educação humanizadora. São os paradigmas que adotamos que constroem o nosso pensar, do qual, por sua vez, surgem as nossas práticas. O paradigma de inclusão que orienta grande parte das políticas de inclusão, frequentemente, leva à segregação. Incluir, incluir-se e ser incluído são termos próximos, mas diferentes, inter-relacionados e complementares. Incluir alguém que é cego na política educacional não significa reunir em uma sala específica todas as pessoas que são cegas. Incluir, nesse caso, é permitir que essas pessoas possam ensinar para as outras pessoas não cegas as formas como elas se relacionam com o mundo. Uma pessoa com deficiência, a priori, não atrapalha as outras diferentes delas por não terem as suas deficiências. Ao contrário, ajudam de uma forma que somente elas poderiam ajudá-las no seu desenvolvimento humano. Igualmente vale para as questões que envolvem gênero, orientação sexual, confissão religiosa, etnia e quaisquer outras diferenças. Diferenças são apenas diferenças que todos nós as temos. Sejamos nós educadores ou educandos, pessoa com deficiência ou não. A desigualdade não nasce das diferenças, mas dos preconceitos, os quais, por sua vez, costumam nascer de um paradigma 
fossilizado. Queremos aqui despertar os nossos sentidos para esses fatos. E é a educação para a liberdade e para a inclusão o instrumento que nos conduz para a superação dos preconceitos e para a convivência com os diferentes.

Recebido em: 10/09/2018

Revisado pelo autor em: 09/10/2018 Aceito para publicação em: 16/11/2018

\section{Notas}

1 Mestre em teologia pela Pontifícia Universidade Católica do Paraná (PUC-PR). Especialista em Assessoria Bíblica pela Escola Superior de Teologia (EST). Bacharel em Teologia. Poeta e militante. Autor do livro: "Entre o Sol e a Lua: um eclipse de amor e poesia". E-mail: poesiaemilitancia@yahoo.com.br

\section{Referências}

BÍBLIA SAGRADA. Nova Pastoral. São Paulo: Paulus, 2014.

BOFF, Leonardo. O cuidado necessário. São Paulo: Vozes, 2012.

CARLEIAL, Liana Maria; OPUSZKA, Paulo Ricardo; KANUFRE, Rosana Aparecida (Orgs.). Políticas e ações deliberativas em Curitiba: diálogo, confiança e mediação. Curitiba: IMAP, 2016.

CNBB - Conferência Nacional dos Bispos do Brasil. Campanha da Fraternidade de 2018: Texto-Base. Brasília: Edições CNBB, 2017.

FREIRE, Paulo. Pedagogia da autonomia. São Paulo: Paz e Terra, 2004.

. Pedagogia do oprimido. São Paulo: Paz e Terra, 2006.

. Pedagogia da esperança: um reencontro com a pedagogia do oprimido. São Paulo: Paz e Terra, 2009.

GADOTTI, Moacir. Os mestres de Rousseau. São Paulo: Cortez Editora, 2004. GUESCHÉ, Adolphe. O sentido: Deus para pensar. São Paulo: Paulinas, 2005. PAPA Francisco. Exortação Apostólica Evangelii Gaudium (A Alegria do Evangelho): sobre o anúncio do Evangelho no mundo atual. São Paulo: Paulus/Loyola, 2014.

Carta Encíclica Laudato Si' (Louvado Seja): Sobre o Cuidado da Casa Comum. Brasília: Edições CNBB, 2015.

RODRIGUES, David (Org.). Inclusão e educação: doze olhares sobre a educação inclusiva. São Paulo: Summus Editorial, 2006. 